\title{
BMC Medical Informatics \\ and Decision Making
}

\section{Medical informatics in an undergraduate curriculum: a qualitative study}

\author{
David L Buckeridge*1,2 and Vivek Goel ${ }^{3}$
}

\begin{abstract}
Address: ${ }^{1}$ Community Medicine Residency Program, Department of Public Health Sciences, University of Toronto, Canada, ${ }^{2}$ Stanford Medical Informatics, Stanford University, School of Medicine Medical School Office Building, Room X-215 251, Campus Drive, Stanford, CA $94305-5479$ USA and ${ }^{3}$ Department of Health Policy, Management and Evaluation, University of Toronto Simcoe Hall, 2nd Floor, 27 King's College Circle, Toronto, Ontario, M5S 1A1 Canada

E-mail: David L Buckeridge* - david.buckeridge@stanford.edu; Vivek Goel - vivek.goel@utoronto.ca

${ }^{*}$ Corresponding author
\end{abstract}

Published: 3 September 2002

BMC Medical Informatics and Decision Making 2002, 2:6

Received: 27 May 2002

Accepted: 3 September 2002

(c) 2002 Buckeridge and Goel; licensee BioMed Central Ltd. This article is published in Open Access: verbatim copying and redistribution of this article are permitted in all media for any non-commercial purpose, provided this notice is preserved along with the article's original URL.

\begin{abstract}
Background: There is strong support for educating physicians in medical informatics, and the benefits of such education have been clearly identified. Despite this, North American medical schools do not routinely provide education in medical informatics.

Methods: We conducted a qualitative study to identify issues facing the introduction of medical informatics into an undergraduate medical curriculum. Nine key informants at the University of Toronto medical school were interviewed, and their responses were transcribed and analyzed to identify consistent themes.

Results: The field of medical informatics was not clearly understood by participants. There was, however, strong support for medical informatics education, and the benefits of such education were consistently identified. In the curriculum we examined, medical informatics education was delivered informally and inconsistently through mainly optional activities. Issues facing the introduction of medical informatics education included: an unclear understanding of the discipline; faculty and administrative detractors and, the dense nature of the existing undergraduate medical curriculum.
\end{abstract}

Conclusions: The identified issues may present serious obstacles to the introduction of medical informatics education into an undergraduate medicine curriculum, and we present some possible strategies for addressing these issues.

\section{Background}

It is important that physicians be educated in medical informatics. Professional bodies [1,2], and commissions [3] support this position and make it clear that education must go beyond computer literacy to address the fundamentals of handling data, information, and knowledge. Educating physicians in medical informatics should ena- ble many things, including appropriate interaction with clinical information systems, and the ability to utilize the Internet to inform themselves and their patients. In short, an education in medical informatics is essential for the many roles of a physician including clinician, educator, researcher, manager, and life-long learner [1]. 
Without a basic education in medical informatics physicians are limited in their ability to make effective use of informatics methods and information technology. Moreover, without appropriate input from physicians skilled in medical informatics, it may be impossible to implement clinical computing infrastructure that meets the needs of clinicians [4]. Physicians and medical students appear to be increasingly aware of this as evidenced by the growing desire for education in medical informatics [57].

Despite calls for education in medical informatics from many directions, it appears that medical informatics is not an established element of undergraduate medical curricula in North America. Most Canadian medical schools have yet to introduce education in medical informatics $[8,9]$, and the situation appears similar in the United States [7]. This study aims to explore issues that might influence the introduction of medical informatics into an undergraduate medical curriculum.

\section{Methods}

A qualitative survey was conducted using key informants from the University of Toronto medical school. The school has an annual enrollment of nearly 200 , and is accredited by the Liaison Committee on Medical Education (LCME). The four-year curriculum follows the traditional North American model of two years of mainly classroom and small group learning, followed by two years of mainly clinical teaching (clerkship).

Purposive sampling began with senior curriculum planners and faculty members known to have an interest in medical informatics. A second phase recruited other faculty members identified through the initial contacts. All faculty members were recruited via a personal email message. In a final phase, students were recruited from different years of the undergraduate medical curriculum. A generic email message was sent to all undergraduate medical students requesting participants for the study. The first student to respond from each year of the curriculum was interviewed.

Data collection occurred during one-hour interviews. The preferred mode of interview was in person, but given the non-personal subject matter, telephone interviews were conducted when necessary. Open-ended questions were used (Table 1). If the first question revealed that a respondent was not aware of medical informatics as a distinct discipline, they were read the following definition [10] before continuing: "Medical informatics is the scientific field that deals with biomedical information, data, and knowledge - their storage, retrieval, and optimal use for problem-solving and decision-making." The interviewer made careful notes during the interview, and inter- viewees subsequently reviewed the notes. A basic set of coding categories was defined $a$ priori from previous studies in the area $[8,11]$, and methods drawn from grounded theory analysis were used to identify themes [12].

\section{Table I: Open ended questions asked of key informants}

How would you describe medical informatics?

Do you feel that it is important to educate medical students in medical informatics?

Are you aware of any ongoing medical informatics education in the medical school?

What issues affect development of medical informatics education in the medical school?

What resources for medical informatics education are you aware of in the medical school?

\section{Results \\ Study participants}

Nine interviews took place between December 1999 and October 2000. All five faculty members who were contacted agreed to be interviewed. Three faculty members were primarily involved in teaching and the other two had primarily administrative roles in the undergraduate medical curriculum. Seven students ultimately responded to the generic email request for participation, and four were interviewed. All interviews were conducted in person with the exception of one student who was interviewed over the telephone. The majority of study participants were male ( 8 of 9 ).

\section{Perceptions of medical informatics}

Some student participants were not aware of medical informatics as a distinct discipline, but most respondents were familiar with the term. Those who were aware of the discipline tended to feel that it was not clearly defined, saying 'the term medical informatics lacks clarity' and 'there is no standard definition'. The discipline was also seen for the most part as applied, and there was some variation in respondents' understanding of breadth of the discipline in relation to technology. Comments from a number of respondents focused on medical informatics as the use of technology and failed to recognize the discipline as encompassing a body of methods and knowledge (e.g. 'medical informatics is the use of information technology in health care'). There was also a tendency for faculty members to be more interested in medical informatics for its ability to facilitate medical education than as a topic of instruction unto itself.

Importance of educating physicians in medical informatics All except one respondent felt that some sort of education in medical informatics was important for physicians. The expected outcome of medical informatics education was 
felt by nearly all participants to include enabling physicians to use information technology in the delivery of clinical care, practice management, and for tasks such as evaluating the quality of individual and population care. However, a minority noted that 'the use of electronic medical records is pretty straightforward', and that physicians don't necessarily need to know what is 'inside the black box' as long as systems are well designed.

Another dominant theme in terms of benefits of education was the perceived influence on physicians' ability to practice evidence-based medicine (EBM). Respondents noted the area of EBM as a whole, as well as commenting on the positive influence of medical informatics education on abilities to locate and evaluate information.

A minor theme noted by some was the need to understand medical informatics in order to 'keep up' with developments in technology. Specific examples were the ability to use information technology for life-long learning, and to be able to interact with increasingly informed patients by understanding information brought by patients to a consultation, and by being able to refer patients to relevant information on the Internet.

\section{Current and planned medical informatics education}

All respondents noted that there were no specific curricular elements for medical informatics. However, there did appear to be a number of related activities, some mandatory and some optional or inconsistently available. Mandatory activities related to medical informatics were delivered through a population health course which addressed areas such as critical appraisal, Evidence-Based Medicine, and evaluation. Optional or inconsistently delivered activities identified included brief hospital information system user training sessions, MEDLINE training sessions, discussion in problem-based learning sessions, informal faculty interactions, and research opportunities. It was also noted by a few respondents that there was considerable use of informatics as a tool in the educational process.

One faculty member acknowledged that the current activities 'do not address the Association of American Medical Colleges objectives specifically', but nonetheless felt that 'the outcome is probably OK'. In general, most faculty members felt that more medical informatics content was probably necessary, and that it should be built into existing courses. Students either had no opinion on the adequacy of their medical informatics education, or had unfavorable opinions. One student noted that 'there is not much, and I am not expecting much'.

There did not appear to be any plans for future activity in undergraduate medical informatics education, either by the faculty of medicine alone, or in combination with others. However, it was noted that an external accreditation body has a task force on the issue, and that the medical school has a task force examining the use of informatics in medical education.

\section{Issues in implementing medical informatics education}

Barriers were more easily identified than enablers. A frequently cited barrier was the lack of understanding of what medical informatics is ('difficult to conceptualize'), and what education in medical informatics will accomplish. Some thought that this lack of clarity has led to a limited acceptance of medical informatics by senior administrators, and an assumption that students will learn what is necessary on their own ('by osmosis'). A number of respondents noted that senior administrators could become enablers if they were convinced of the rationale for education, and that they would present a considerable barrier if they were not convinced.

As with administrators, faculty members were also seen to be potentially both barriers and enablers. Responses from both faculty and students identified a 'split among the faculty' between those inclined towards computers, and those opposed to computing. One student felt that there was a 'gap between faculty and students' in terms of computer literacy. While one respondent felt that there was no lack of faculty skilled in medical informatics, most study participants felt that the limited number of faculty with medical informatics experience posed a barrier in the form of limited resources for teaching, especially in applied clinical informatics. Interestingly, the enthusiasm of faculty members for the use of medical informatics in $d e$ livering education was noted by some to be a barrier to developing education in medical informatics.

Another consistently identified barrier was the 'packed' nature of the undergraduate medical curriculum. One respondent felt that there was little chance of medical informatics being incorporated into the curriculum given that 'core' additions to the curriculum had recently been refused.

Enablers to medical informatics education were almost exclusively identified as being external to the Faculty. These included moves by accreditation and licensing bodies towards the use of computers for test delivery and the assessment of computing infrastructure for accreditation. The general movement of the university towards supporting informatics was also identified as an enabling factor. Some respondents also felt that the work of related academic and research groups (e.g. health services research), and the library also facilitated education in medical informatics. 


\section{Discussion}

Participants did not have a clear understanding of medical informatics as a discipline. Others have noted that health professionals tend to not have a clear picture of medical informatics [7], and this should not be surprising given continued debate over the nature of medical informatics within the discipline [13]. Nevertheless, respondents generally agreed on the importance of educating physicians in medical informatics, and benefits of education were consistently identified. This appreciation of perceived benefits of medical informatics education is consistent with findings in other settings $[6,14,15]$.

Despite participants consistently identifying benefits of medical informatics education, at this medical school, education was delivered informally and inconsistently through mainly optional activities. This situation appears to be typical of North American medical schools [7,9]. We identified a number of issues that may help explain why medical informatics has not made substantial inroads into the undergraduate curriculum. These issues included: lack of a clear understanding of medical informatics as a discipline; limited support for informatics education among administrators and faculty; and, the 'packed' nature of the undergraduate curriculum. While these issues can present serious obstacles to introducing medical informatics education into an undergraduate medical curriculum, it should be possible to address them.

The lack of a clear understanding of the discipline of medical informatics and limited support for medical informatics education are related issues. Even though there was strong support for the expected benefits of medical informatics education, difficulty in conceptualizing medical informatics education seemed to present a barrier to envisioning the need for such education. The difficulty in conceptualizing medical informatics education seemed to be exacerbated by a tendency to conflate education in medical informatics with the use of computers in medical education. This mixing of concepts may explain why there was an expectation that students would pick up the necessary medical informatics skills by interacting with computing resources in the educational process.

Medical informatics is however much more than interacting with computing resources [10], and the expected benefits of medical informatics education are not likely to be realized through incidental interactions with computers [1]. Effort must be expended to ensure that medical school faculty and administrators are aware of the nature of the discipline of medical informatics, and how education in medical informatics is necessary to provide future physicians with essential skills. Departments of medical informatics, professional associations in medical infor- matics, and associations of medical schools are obvious candidates for this task.

The dense nature of the undergraduate medical curriculum presents a barrier to the incorporation of new material. Direct introduction of a new medical informatics course would likely be difficult, requiring support from influential champions. Incorporation of medical informatics content into existing courses or problem based learning sessions [5] may be easier to accomplish than introducing a new course. Medical schools in Europe have incorporated medical informatics principles into existing medical school courses for a number of years now [16], and this approach appears to have been successful in the European setting [17]. However, given our findings about the limited understanding of medical informatics, care must be taken to ensure that specific learning objectives are included and evaluated in existing courses and that there is not just an implicit expectation that medical informatics principles will be learnt.

Given the similarity of the University of Toronto medical school to most medical schools in North America, we expect that our findings are generally representative of opinions and activities on this topic in other North American medical schools, and the limited literature on the subject seems to support this expectation [7-9]. However, care should be taken in generalizing the findings, as the goal of the study was not to produce findings generalizable to all North American medical schools. On the contrary, the goal was to develop a deep understanding of the problems faced at a single medical school. The findings are valuable in that they constitute a model of the problems faced in incorporating medical informatics education into an undergraduate medical curriculum. This model can now be used in future qualitative studies at other locations (e.g., to compare in-depth descriptions of problems encountered at different locations), or as the basis for developing a quantitative questionnaire to be administered across a number of locations (e.g., to determine at a more superficial level the extent to which similar problems are seen in many locations).

The qualitative method used for this study allowed an indepth exploration of issues around medical informatics in a manner that is difficult to accomplish with a quantitative survey. However, despite pursuit of contradictory perspectives and methods aimed at safeguarding validity, qualitative analysis remains subjective by its very nature. Care was taken to report only consistently identified themes and to note dissent when present, but it is always possible that themes may have been interpreted differently with a different selection of respondents. 


\section{Competing Interests}

None

\section{Authors' Contributions}

DLB conceived of and designed the study, conducted the interviews, analyzed the results and drafted the manuscript. VG designed the study, contributed to the analysis, and contributed to the manuscript.

\section{Acknowledgments}

Financial assistance for this study was provided by a resident fellowship in medical education from the AMS-Wilson Foundation. The study participants are gratefully acknowledged for offering their thoughts on the study objectives and reviewing transcripts of their comments. However, responsibility for the interpretation of participants' comments rests solely with the authors.

\section{References}

I. Anonymous: Contemporary issues in medicine - medical informatics and population health: report II of the Medical School Objectives Project. Academic Medicine 1999, 74:|30-4|

2. Anonymous: Recommendations of the International Medical Informatics Association (IMIA) on education in health and medical informatics. Methods of Information in Medicine 200I, 39:267-77

3. Pew Health Professions Commission: Recreating Health Professional Practice for a New Century: The Fourth Report of the Pew Health Professions Commission. In: Book Recreating Health Professional Practice for a New Century: The Fourth Report of the Pew Health Professions Commission. Pew Health Professions Commission; 1998

4. Lorenzi NM, Riley RT, Blyth AJ, Southon G, Dixon BJ: Antecedents of the people and organizational aspects of medical informatics: review of the literature. Journal of the American Medical Informatics Association 1997, 4:79-93

5. Hasman A, Boshuizen HP: Medical informatics and problembased learning. Methods of Information in Medicine 200I, 40:78-82

6. McClaran J, Snell L, Duarte-Franco E: Continuing educational needs in computers and informatics. McGill survey of family physicians. Canadian Family Physician 2000, 46:839-47

7. Staggers N, Gassert CA, Skiba DJ: Health professionals' views of informatics education: findings from the AMIA 1999 spring conference. Journal of the American Medical Informatics Association 2000, 7:550-8

8. Buckeridge DL, Goel V: Health informatics education: an opportunity for public health in Canada. Canadian Journal of Public Health 2001, 92:233-6

9. Moehr JR, Grant AM: Medical informatics and medical education in Canada in the 2 Ist century. Clinical and Investigative Medicine 2000, 23:275-250

10. Shortliffe E, Perreault L, Wiederhold G, Fagan L, eds: Medical Informatics: Computer Applications in Health Care and Biomedicine, New York: Springer-Verlag; 2001

II. Grant AM, Tremblay K: The need for a coherent curriculum and supported infrastructure in health informatics education - the HEALNet experience. Health Evidence Application and Linkage Network. International Journal of Medical Informatics 1998, 50:165-70

12. Strauss A, Corbin J: Basics of Qualitative Research, Thousand Oaks, CA: Sage; 1998

13. Protti DJ, van Bemmel JH, Gunzenhuser R, Haux R, Warner H, Douglas JV, Lang E: Can health/medical informatics be regarded as a separate discipline? Methods of Information in Medicine 1994, 33:318-26

14. Hasman A: Education and health informatics. International Journal of Medical Informatics 1998, 52:209-16

15. Jerant AF, Lloyd AJ: Applied medical informatics and computing skills of students, residents, and faculty. Family Medicine 2000, 32:267-72

16. Tuinstra $C L$ : Integration of medical informatics with other courses in the medical curriculum. Methods of Information in Medicine. 1989, 28:243-5
17. Zvarova J, Vacek Z: Medical education system in Czechoslovakia: achievements and perspectives of medical informatics education. Methods of Information in Medicine. 1989, 28:246-9

\section{Pre-publication history}

The pre-publication history for this paper can be accessed here:

http://www.biomedcentral.com/1472-6947/2/6/prepub
Publish with BiolMed Central and every scientist can read your work free of charge

"BioMedcentral will be the most significant development for disseminating the results of biomedical research in our lifetime." Paul Nurse, Director-General, Imperial Cancer Research Fund

Publish with BMC and your research papers will be:

- available free of charge to the entire biomedical community

- peer reviewed and published immediately upon acceptance

- cited in PubMed and archived on PubMed Central

- yours - you keep the copyright

Submit your manuscript here:

http://www.biomedcentral.com/manuscript/
BioMedcentral.com editorial@biomedcentral.com 